\title{
ИНТЕГРАЦИЯ ИММИГРАНТОВ В ЕС И РОССИИ: РАЗНИЦА В ПОДХОДАХ
}

Аннотация. В статье анализируются различия подходов к интеграции мигрантов, существуюшие в Европейском союзе и России. В ЕС иентром интеграџионной политики служит обеспечение прав иностранных граждан и их социально-экономическая включённость в жизнь принимающих обществ. Россия делает ставку на вре́менную трудовую миграџию, что обуславливает отсутствие в миграчионной политике страны разработанной системь интеграционных мер. На концептуальном уровне в России пока превалирует понимание интеграции в его культурно-языковом аспекте при выделении роли государственных структур в реализации интеграционных мер.

Ключевые слова: Европейский союз, Россия, мигращия, интеграџия, адаптащия, мигран$m b l$.

Принятый 10 декабря 2018 г. на межправительственной конференции в Марракеше Глобальный договор о безопасной, упорядоченной и легальной миграции особо подчёркивает необходимость создания для мигрантов условий, обеспечивающих полную социальную интеграцию и сплочённость ${ }^{1}$. Договор ставит перед национальными государствами цели содействия интеграции мигрантов через трудоустройство, воссоединение семей, образование, недискриминацию и доступ к здравоохранению2 ${ }^{2}$.

Миграционная политика в широком понимании касается не только формальных правил въезда, проживания и трудоустройства легальных иммигрантов на территории принимающей страны, но затрагивает и такие весьма важные вопросы как социально-экономическая интеграция, культурная адаптация, и права и обязанности граждан третьих стран. Меры, предпринимаемые принимающей страной по интеграции иммигрантов способны решить проблемы дискриминации, социального иждивенчества и геттоизации, которые становятся плодотворной почвой для радикализации части иммигрантского сообщества и проявления социальной нетерпимости среди местного населения.

Российская Федерация, как и 19 стран - членов $\mathrm{EC}^{3}$, поддержала принятие Глобального договора о безопасной, упорядоченной и легальной миграции на Генеральной Ассамблее ООН 19 декабря 2018 г. РФ занимает третье место после Соединённых Штатов и Германии по приёму иммигрантов. Великобритания, Франция и Испания также входят в десятку стран, принимающих наибольшее число мигрантов ${ }^{4}$. Как для ЕС, так и для России иммиграция служит важным источником прироста населения. Кроме того, и страны Евросоюза и Россия рассмат-

(ㄷ Биссон Любовь Сергеевна - кандидат политических наук, старший научный сотрудник Отдела исследований европейской интеграции ИЕ РАН. Адрес: 125009, Россия, Москва, ул. Моховая, д. 11, стр. 3. Email: bisson@ieras.ru.

DOI: http://dx.doi.org/10.15211/vestnikieran62018112118

${ }_{1}^{1}$ Глобальный договор о безопасной, упорядоченной и легальной миграции С. 8.

2 Там же. С. 16.

${ }^{3}$ Венгрия, Польша и Чехия проголосовали против, Австрия, Болгария, Италия, Латвия, Румыния воздержались, Словакия не голосовала.

${ }^{4}$ World Migration Report 2018, IOM: Geneva. P. 19. 
ривают законную трудовую миграцию в качестве необходимого условия дальнейшего экономического развития. Новая Концепция государственной миграционной политики РФ на 20192025 гг., принята 31 октября 2018 г., впервые ставит задачи социально-экономического, пространственного и демографического развития прежде вопросов обеспечения безопасности в списке целей миграционного регулирования (см. табл. 1).

Цели миграционной политики РФ 2012, 2018 гг.

Таблица 1

\begin{tabular}{|l|l|}
\hline \multicolumn{1}{|c|}{ Концеепция 2012} & \multicolumn{1}{|c|}{ Концеепция 2018} \\
\hline $\begin{array}{l}\text { - стабилизация и увеличение численности постоян- } \\
\text { ного населения }\end{array}$ & $\begin{array}{l}\text { - решение задач в сфере социально-экономического, } \\
\text { пространственного и демографического развития }\end{array}$ \\
\hline - обеспечение национальной безопасности & - обеспечение безопасности государства \\
\hline $\begin{array}{l}\text { - содействие обеспечению потребности экономики в } \\
\text { рабочей силе, модернизации, инновационном разви- } \\
\text { тии и повышении конкурентоспособности отраслей }\end{array}$ & $\begin{array}{l}\text { - поддержание межнационального и межрелигиозного } \\
\text { мира и согласия в обществ }\end{array}$ \\
\hline & - защита национального рынка труда \\
\hline & - повышение качества жизни населения \\
\hline
\end{tabular}

\section{Интеграция - неотъемлимая часть миграционной политики ЕС}

Для Европейского союза, который уже на протяжении более полувека испытывает постоянный приток не только ищущих убежище из кризисных регионов мира, но и принимает значительное число трудовых мигрантов и членов их семей, присутствие граждан третьих стран из вре́менного явления превратилось в факт повседневной жизни. По последним данным Евростата, на 1 января 2017 г. в 28 странах - членах ЕС проживало более 21 млн граждан третьих-стран, что составляет 4,2\% от общего населения Союза ${ }^{1}$. Однако вплоть до конца 1990-х гг. в странах Евросоюза доминировала «философия о возвращении иммигрантов на родину» (return philosophy), т.е. представление о том, что иммиграция носит только временный характер и никаких мер для интеграции не требуется. Однако постепенно становилось очевидным, что те иммигранты, которые прибывали в страны Евросоюза на протяжении долгих лет, не собираются возвращаться домой и при этом всё ещё плохо интегрированы в принимающее сообщество. Кроме того, существенная доля граждан третьих стран, проживающих сегодня в странах Европейского союза, прибывает по линии воссоединения семьи. На начало 2000-х гг. около $50 \%$ всех иммигрантов прибывало в ЕС по линии семейного воссоединения. Вместе с положительным эффектом для рынков труда приток иммигрантов из третьих стран принёс с собой серьёзные вызовы для социальной стабильности и безопасности. Это поставило Европейский союз перед вопросом: в какой степени наделение легальных иммигрантов широкими социально-экономическими правами может способствовать интеграции иммигрантов в принимающее сообщество?

Как правило, принято выделять четыре основных измерения интеграции иммигрантов ${ }^{2}$ : структурное, культурное, социальное и идентификационное. В результате структурной интеграции приобретаются права и доступ к членству в принимающем обществе и его основным институтам (образование, здравоохранение, рынок труда, гражданство и т.д.). Культурная интеграция выступает в качестве условия включённости иммигранта в определённый существующий культурный контекст. Социальная интеграция проявляется в сфере частной (брак, семья, дружба) и коллективной жизни иммигрантов (т.е. на уровне общин и добровольных ор-

\footnotetext{
${ }^{1}$ Eurostat, Migration and migrant population statistics - Statistics Explained, March 2018. URL: https://ec.europa. eu/eurostat/statistics-explained/index.php/Migration_and_migrant_population_statistics (дата обращения 03.12.2018).

${ }^{2}$ Heckmann F. The integration of immigrants in European societies: national differences and trends of convergence / F. Heckmann, D. Schnapper. Stuttgart: Lucius \& Lucius DE, 2003. P. 10.
} 
ганизаций), в их контактах с местным населением. Чувство принадлежности к принимающему сообществу на субъективном уровне является результатом идентификационной интеграции.

На уровне Европейского союза под интеграцией понимается прежде всего структурное её измерение, а именно, вовлечённость иммигрантов в социально-экономическую жизнь принимающей страны. Таким образом, успех интеграции оценивается в зависимости от уровня и условия труда и жизни граждан третьих стран на территории Евросоюза ${ }^{1}$. Подход к интеграции иммигрантов на уровне ЕС в наименьшей степени определяется представлениями о том, что такое нация, культура и национальная идентичность, акцент на которых скорее характерен для интеграционных стратегий и политик отдельных государств-членов.

Политика Евросоюза в сфере интеграции граждан третьих стран зиждится на двух опо$\operatorname{pax}^{2}$. Первая представлена законодательством ЕС в сфере легальной иммиграции. Речь идёт о юридически обязывающих наднациональных нормах, в первую очередь директивах 2003/86/ $\mathrm{EC}^{3}$ и 2003/109/EC ${ }^{4}$ о праве на семейное воссоединение и о статусе долгосрочного резидента, и с 2011 г. директива 2011/98/ЕС о едином документе и своде прав легальных иммигрантов в Европейском союзе 5 . Перечисленные директивы предполагают, что наделение иммигрантов определёнными правами и статусом максимально способствуют их интеграции в принимающее сообщество. В то же время при реализации директив государства-члены в праве устанавливать интеграционные меры в качестве одного из предварительных условиий получения прав и легального статуса, а также воссоединения семей. В том числе речь идёт и прохождении интеграционных тестов на знание языка и культуры ещё до въезда и получения разрешительных документов - так называемая «интеграция за границей». На уровне стран - членов ЕС наблюдается общая тендендия: в интеграционных программах приоритет отдаётся знанию языка, экономической независимости приезжающих граждан третьих стран. Права прямым образом связаны с готовностью иммигрантов интегрироваться.

Однако на наднациональном уровне действует обратная логика. Вторая опора политики ЕС по интеграции иммигрантов содержит совокупность юридически не обязывающих мер, мероприятий и принципов, которые могут быть обозначены как рамки интеграции граждан третьих стран в Европейском союзе (EU Framework on Integration) ${ }^{6}$. Рамки представляют собой механизм мягкого права и пример мноуровневого управления. Главным инструментом служат общие базовые принципы интеграции иммигрантов (ОБПИ), состоящие из 11 пунктов ${ }^{7}$ :

1. интеграция является динамичным, двусторонним процессом взаимного приспособления всех иммигрантов и граждан стран-членов;

\footnotetext{
${ }^{1}$ Entzinger H. Benchmarking in Immigrant Integration. Report for the European Commission / H. Entzinger, R. Biezeveld. Rotterdam, 2003. 53 p.

${ }_{2}$ Carrera S. In Search of Perfect Citizen? The Intersection between Integration, Immigration and Nationality in the EU. Leiden: Martinus Nijhoff Publishers, 2009. P. 3.

${ }^{3}$ Council Directive 2003/86/EC of 22 September 2003 on the right to family reunification // Official Journal of the European Union. 2003. L 251. P. 12-18.

${ }^{4}$ Council Directive 2003/109/EC of 25 November 2003 concerning the status of third-country nationals who are longterm residents // Official Journal of the European Union. 2004. L 16. P. 44-53.

${ }^{5}$ Council Directive 2011/98/EU of the European Parliament and of the Council of 13 December 2011 on a single application procedure for a single permit for third-country nationals to reside and work in the territory of a Member State and on a common set of rights for third-country workers legally residing in a Member State // Official Journal of the European Union. L 343. 23.12.2011. P. 1-9.

${ }^{6}$ Communication from the Commission to the Council, the European Parliament, the European Economic and Social committee and the Committee of the Regions - A Common Agenda for Integration - Framework for the Integration of Third-Country Nationals in the European Union COM/2005/0389 final. P. 3.

7 Annex I of The Hague Programme: Strengthening Freedom, Security and Justice in the European Union, point 1.5 (European Council, 2004). URL: http://ue.eu.int/ueDocs/cms_Data/docs/pressData/en/jha/82745.pdf (дата обращения 03.12.2018).
} 
2. интеграция подразумевает уважение основных ценностей Европейского союза;

3. занятость является ключевым элементом интеграционного процесса;

4. базовые знания языка, история институтов принимающего общества крайне необходимы для интеграции;

5. усилия в сфере образования важны для подготовки иммигрантов к более активной и успешной жизни;

6. доступ иммигрантов как к институтам, так и общественным благам и сфере услуг должен быть основан на принципе равенства с правом граждан стран-членов и недискриминации;

7. частое взаимодействие между иммигрантами и гражданами стран-членов представляет собой важнейший механизм интеграции;

8. должна быть гарантирована практика культурного и религиозного многообразия, признанная Хартией основных прав Европейского союза;

9. участие иммигрантов в демократическом процессе и формировании интеграционной политики и стратегий, особенно на местном уровне, способствует интеграции;

10. интеграционные стратегии и меры должны быть составной частью соответствующих сфер политики и уровней управления;

11. разработка чётких целей, индикаторов и механизмов оценки политик, прогресса и более эффективного обмена информации также является частью процесса интеграции.

В 2016 г. Европейская комиссия представила План действий по интеграции граждан третьих стран, которые закрепляют ОБПИ, а также особое место уделяют необходимости мер по интеграции мигрантов ещё до их въезда в Европейский союз. В этом прослеживается влияние подхода, который преобладает на уровне государств-членов. Для реализации выдвинутых принципов был учреждён фонд «Убежище, миграция и интеграция» (2014-2020) с общим бюджетом более 3 млрд евро на семилетний период. Стоит отметить, что получателями средств фонда являются не только государства-члены, но и гуманитарные и неправительственные организации, а также образовательные и исследовательские учреждения, деятельность которых направлена на интеграцию граждан третьих стран.

\section{Россия делает ставку на временную миграцию}

В Российской Федерации подавляющая часть иностранных граждан относится к категории временно пребывающих. Именно с этим связано, то, что до настоящего времени в России на государственном уровне не были приняты специальные программы адаптации и интеграции иммигрантов. Тем не менее каждый год российское гражданство приобретает более 200 тыс. иностранцев, а число прибывающих в Россию на постоянное место жительства составляет более 400 тыс. человек ежегодно (данные за 2016-2018 гг.) ${ }^{1}$. Иностранные работники, главным образом из безвизовых стран, приезжая в Россию на заработки, нередко стремятся изменить свой статус и получить разрешение на временное проживание ${ }^{2}$, а в дальнейшем вид на жительство или гражданство, создают семьи, их дети получают образование уже в российских школах. Всё это требует от законодателей и Главного управления по вопросам миграции ${ }^{3}$ новых инициатив и разработки долгосрочных мер в сфере регулирования легальной иммиграции.

\footnotetext{
${ }^{1}$ МВД России, Сводка основных показателей деятельности по миграционной ситуации в Российской Федерации за январь-ноябрь 2018 га. URL: https://xn--b1aew.xn--p1ai/Deljatelnost/statistics/migracionnaya/item/15252649/ (дата обращения: 22.12.2018).

2 Срок действия РВП составляет три года.

${ }^{3}$ В 2016 году Федеральная миграционная служба вошла в состав МВД.
} Научно-аналитический вестник ИЕ РАН, 2018, №6 
В рамках реализации государственной национальной политики в 2016 г. была принята подпрограмма по социокультурной адаптации и интеграции мигрантов с общим бюджетом 695 млн рублей на период 2017-2025 гг. ${ }^{1}$ Однако подпрограмма никак не подкреплена ни нормативно-правовой базой, ни чётким планом действий. В августе 2017 г. полномочия по социальной и культурной адаптации мигрантов были возложены на Федеральное агентство по делам национальностей (ФАДН). Агентство приступило к разработке правовых механизмов, включая соответствующий понятийный аппарат. В 2017 г. ФАДН представило проект федерального закона «О социальной и культурной адаптации и интеграции иностранных граждан в Российской Федерации», в котором впервые даётся определение социальной и культурной адаптации и интеграции, также понимаемых как двусторонний процесс и представляющих собой «совокупность действий органов государственной власти, органов местного самоуправления, институтов гражданского общества и иностранного гражданина, направленных на его включение в социальное и культурное пространство российского общества» ${ }^{2}$. В случае адаптации речь идёт об иностранцах временно пребывающих на территории России с целью осуществления трудовой деятельности, при интеграции - о гражданах третьих стран, прибывающих для временного или постоянного проживания.

В качестве главного мероприятия по интеграции и адаптации в законопроекте обозначено обучение русскому языку, основам законодательства и истории, а также информирование о культуре и традициях, правилах поведения, принятых в российском обществе. Напомним, что с 2015 г. единственным инструментом интеграции иммигрантов в России служит обязательный комплексный экзамен на знание русского языка, истории и основ законодательства для всех категорий иностранных граждан за исключением высококвалифицированных специалистов. В России существуют лишь отдельные элементы адаптационных мер, которые не являются частью миграционной политики: бесплатное обучение детей мигрантов в российских школах, бесплатная медицинская помощь в экстренных случаях, бесплатные роды для женщин-мигрантов ${ }^{3}$.

Таким образом, в российском подходе к интеграции иммигрантов превалирует культурное, а не социально-экономическое измерение. В то время как при выстраивании миграционной политики Европейский союз во главу угла ставит концепцию прав человека, закрепляя базовые права граждан третьих стран на семейную жизнь, достойные условия труда и т.п., в новой редакции Концепции миграционной политики России не упомянуты права, которыми обладают граждане третьих стран на территории РФ, речь ведётся лишь о правилах, услугах, процедурах ${ }^{4}$.

Проект федерального закона предполагает возможность для иммигрантов заключать с органами власти адаптационный или интеграционный контракт (в зависимости от целей: трудовая деятельность или проживание). Заключение адаптационного контракта предоставит иностранному гражданину право на получение отсрочки для прохождения комплексного экзамена при получении разрешения на работу или патента на срок действия адаптационного контракта.

Ответственность за интеграцию возлагается на органы власти и местного самоуправле-

\footnotetext{
${ }^{1}$ Постановление Правительства РФ от 29.12.2016 №1532 (ред. от 07.04.2018) «Об утверждении государственной программы Российской Федерации «Реализация государственной национальной политики».

${ }^{2}$ Проект Федерального закона «О социальной и культурной адаптации и интеграции иностранных граждан в Российской Федерации». URL: fadn.gov.ru/system/attachments/attaches/000/028/.../01_Проект_Ф3_07-09-2017 (дата обращения: 29.12.2018).

${ }^{3}$ Полетаев Д.В. От недоверия к солидарности или новому недоверию? Миграционный опыт России в мировом контексте // Валдайские записки. №97. 2018. С. 11.

${ }^{4}$ Ивахнюк И.В. Миграция и международное право: Рабочая тетрадь РСМД №45/2018. М., РСМД. С. 11.
} Научно-аналитический вестник ИЕ РАН, 2018, №6 
ния. В тексте ФАДН лишь ме́льком упомянута возможность участия институтов гражданского общества. Для России в целом характерно настороженное отношение к участию неправительственного и некоммерческого сектора в работе с иммигрантами. Это существенным образом отличается от ситуации в Европейском союзе, где НКО и НПО активно привлекаются к частно-государственному партнёрству в реализации мер по интеграции граждан третьих стран. Исследователи отмечают негативные последствия такого положения дел в России. В условиях, когда государство и органы власти не способны обеспечить мигрантам защиту их трудовых прав, доступ к базовым услугам (жильё, здравоохранение, образование) в обществе создаются параллельные закрытые структуры взаимопомощи среди мигрантов, что в конечном итоге может способствовать социальной разобщённости и распространению радикальных взглядов среди иммигрантов и угрожать безопасности страны ${ }^{1}$.

Обеспечить легальный доступ иммигрантам на территорию страны - вовсе не достаточное условие максимизации выгоды от их пребывания, к которому стремятся принимающие страны. В условиях сокращения и старения населения, недостатка рабочей силы, имеющих долгосрочные последствия, привлечение иммигрантов не может носить сугубо тактический характер и должно учитывать необходимость разработки мер по интеграции иностранцев, проживащих и работающих на долгосрочной основе. Как отмечено в официальном заявлении к Глобальному договору ООН, Россия будет «сохранять открытость для иностранных граждан, которые рассматривают её в качестве страны с благоприятными условиями для удовлетворения своих экономических, социальных и культурных потребностей» ${ }^{2}$. Это в равной степени относится и к странам Европейского союза, которые, несмотря на рост правых партий, выступающих с жёстких позиций по отношению к регулированию миграционных потоков, будут продолжать привлекать трудовых мигрантов для развития своих экономик и поддержания демографического баланса. Перед принимающими странами встаёт также проблема интеграции второго и третьего поколений мигрантов, которые в наибольшей степени могут быть подвержены радикализации, ощущая, с одной стороны, оторванность от исторической родины, на которой они не бывали, родившись в принимающей стране, и сталкиваясь с ксенофобией и дискриминацией, с другой. В этой связи государственная миграционная политика, как отмечено в Глобальном договоре ООН, призвана служить созданию «инклюзивных и сплочённых обществ путём расширения прав и возможностей мигрантов, $[\ldots]$ путём поощрения взаимодействия мигрантов и принимающего общества при осуществлении прав и обязанностей по отношению друг к другу, в том числе касающихся соблюдения национальных законов и уважения обычаев страны назначения».

\section{Список литературы}

Биссон Л.С. Миграция и социальное развитие Европы: фактор интеграции иммигрантов / Социальное развитие Европы: проблемы и перспективы. М., 2016. С. 111-119.

Ивахнюк И.В. Миграция и международное право: Рабочая тетрадь РСМД №45/2018. М., РСМД. 36 с.

\footnotetext{
${ }_{2}^{1}$ Полетаев Д.В. 2018. С. 7.

2 МИД РФ. Заявление Российской Федерации к Глобальному договору о безопасной. упорядоченной и легальной миграции, Марракеш. 11 декабря 2018 г.. 13.12.2018. URL: http://www.mid.ru/ru/foreign_policy/news//asset_publisher/cKNonkJE02Bw/content/id/3440694 (дата обращения: 24.12.2018).
} 
Миграционные проблемы в Европе и пути их решения / Под ред. Н.Б. Кондратьевой (отв. ред.), О.Ю. Потемкиной. - М. : Ин-т Европы РАН , 2015. 144 с.

Полетаев Д.В. От недоверия к солидарности или новому недоверию? Миграционный опыт России в мировом контексте // Валдайские записки. №97, 2018. 23с.

\section{References}

Bisson L.S. Migraciya i social'noe razvitie Evropy: faktor integracii immigrantov / Social'noe razvitie Evropy: problemy i perspektivy. M., 2016. S. 111-119.

Carrera S. In Search of Perfect Citizen? The Intersection between Integration, Immigration and Nationality in the EU. - Leiden: Martinus Nijhoff Publishers, 2009. 532 p.

Entzinger H. Benchmarking in Immigrant Integration. Report for the European Commission / H.Entzinger H., R.Biezeveld. Rotterdam, 2003. 53 p.

Heckmann F. The integration of immigrants in European societies: national differences and trends of convergence / F. Heckmann, D. Schnapper. Stuttgart, 2003. 261 p.

Ivahnyuk I.V. Migraciya i mezhdunarodnoe pravo: Rabochaya tetrad' RSMD №45/2018. M., RSMD. $36 \mathrm{~s}$.

Migracionnye problemy v Evrope i puti ih resheniya. Ed. by Kondratieva N.B. Moscow, 2015. $144 \mathrm{~s}$.

Poletaev D.V. Ot nedoveriya k solidarnosti ili novomu nedoveriyu? Migracionnyj opyt Rossii v mirovom kontekste // Valdajskie zapiski. 2018. №97. 23 s.

\section{Immigrant Integration in the EU and Russia: Difference in Approaches}

Author. Lyubov Bisson, Candidate of Sciences (Politics), Senior Research Associate of the Department of European Integration Studies, Institute of Europe, Russian Academy of Sciences. Address: 11-3, Mokhovaya str., Moscow, Russia, 125009. E-mail: bisson @ieras.ru.

Abstract. The article analyzes the differences in approaches to the integration of migrants that exist in the European Union and Russia. In the EU, integration policy is ensuring the rights of foreign citizens and their socio-economic inclusion in the life of host societies. Russia relies on temporary labour migration, which explains the absence of a developed system of integration measures in the country's migration policy. At the conceptual level, in Russia prevails understanding of immigrant integration in its cultural and linguistic aspect with the emphasis on the role of state in the implementation of integration measures.

Key words: European Union, Russia, migration, integration, adaptation, migrant.

DOI: http://dx.doi.org/10.15211/vestnikieran62018112118 